\title{
ИНТЕРНЕТ-ТОРГОВЛЯ И ЛОГИСТИКА РОССИЙСКОГО Е-СОММЕRСЕ В СОВРЕМЕННОЙ ФАЗЕ РАЗВИТИЯ РЫНКА: ЭКОНОМИКА РОСТА ЦИФРОВЫХ ПЛАТФОРМ В 2020-2025 ГГ.
}

\author{
(c) 2021 Михайлюк Михаил Владимирович \\ доктор экономических наук, доцент, \\ профессор кафедры логистики и управления транспортными системами \\ Ростовский государственный университет путей сообщения, Россия, Ростов-на-Дону \\ E-mail: Mihailuk.M@gmail.com
}

В статье представлено авторское видение специфики, драйверов и ограничений современного роста и масштабирования маркетплейсов в отечественной Интернет-торговле, стратегическим маркером которых выступает региональный фокус при увеличении внутриотраслевых инвестиций в фулфилмент, последнюю милю и логистику экспресс-доставки. Результаты работы - обоснование автором ограничений и сложностей в развитии е-commerce в России, а также научно-практическая переоценка его роли и значения в товароснабжении потребительского сектора. Область применения - управление экономикой затрат в системе логистического менеджмента и масштабирования бизнес-модели онлайн-ритейла с учетом его высокой капиталоемкости относительно традиционной торговли.

Ключевые слова: маркетплейс, фулфилмент, последняя миля, экспресс-доставка, Интернетторговля

Пандемия и системный демонтаж концепции перепродавцов на потребительском рынке переводят сегодня онлайн-ритейл в плоскость трансформации, где просматривается новое качество и новые тенденции его развития (рис. 1).

В 2020 г. электронные площадки показали опережающий прирост товарооборота (+108\%) до 725 млрд. руб. против 1,725 трлн. руб. выручки интернет-магазинов (+38\%). Однако, более показательным помимо опережающей динамики развития маркетплейсов является привлечение ими более демократичной аудитории покупателей. Это позволило е-commerce площадкам в 2020 г. реализовать 405 млн. заказов со средним чеком 1780 руб. (через интернет-магазины совершено 278 млн. покупок, средний чек 6205 руб.) [1, с. 23].

На уровне институциональной трансфор-

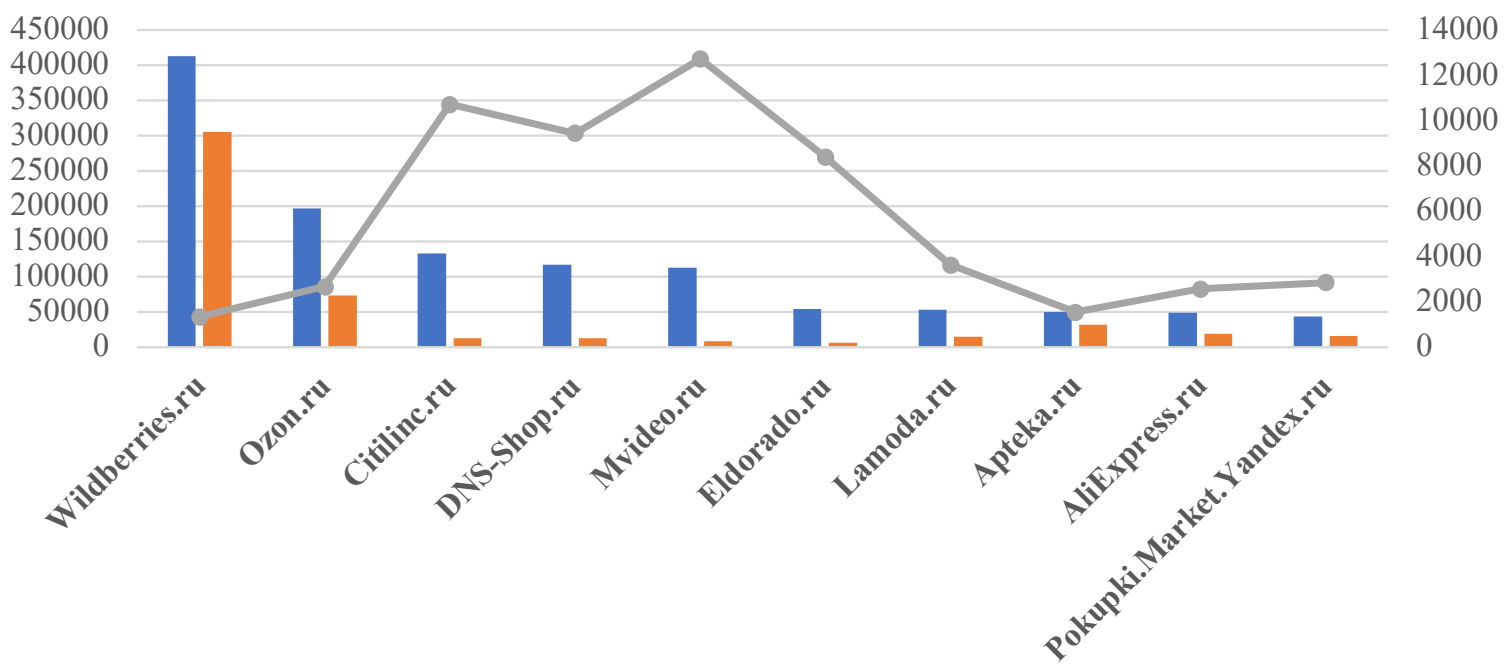

— Выручка, млн. руб. (левая шкала) Заказы, тыс./год (левая шкала)

— Средний чек, тыс. руб. (правая шкала)

Puc. 1. ТОП-10 крупнейших интернет-магазинов в России по итогам 2020 г. [9, с. 44] 
мации Интернет-торговли наблюдается внутреннее дробление электронных площадок, среди которых конкуренцию универсальным маркетплейсам составляют нишевые торговые площадки: в 2020-2021 гг. можно отметить появление более 20 таких цифровых платформ в сегментах FMCG, DIY, fashion и др. Как показывает мировая практика, нишевые маркетплейсы имеют значительный потенциал, а их роль и рыночная власть будут только возрастать [2].

Конкуренция маркетплейсов обеспечила кратное повышение гибкости онлайн-платформ для продавцов $(40 \%-$ ИП), что позволяет им больше концентрироваться на управлении продуктом и повышении своей конкурентоспособности.

Tак, в Ozon их количество на конец июня 2021 г. утроилось по сравнению с 2020 г. Приток продавцов из регионов стимулирует интенсивность строительства Ozon фулфилментфабрик и сортировочных центров. При этом, рост маркетплейсов и закрепление в структуре онлайн-торговли позволяет им отбирать поставщиков, особенно на нишевые площадки, которые позиционируют себя как платформы, на которых предлагается именно качественная продукция («ВсеИнструменты.ру» и др.).

Обеспечивая малому и среднему бизнесу возможность увеличивать производство и масштабировать продажи, расширяя их географию, маркетплейсы постепенно усиливают свою переговорную позицию, что позволяет им на постоянной основе изменять экономику продаж на площадке:

- повышать \% комиссии;

- вводить новые статьи затрат (оплата хранения и др.);

- и др.

Так, в 2021 г. отдельные маркетплейсы «несколько раз меняли политику в отношении тарификации по хранению товаров на складе. Вызвано это тем, что им крайне невыгодно хранить товары с низкой оборачиваемостью» $[1$, c. 25]. Ослабление данного тренда возможно только в результате возрастания конкурентного давления других электронных площадок, для расширения которого в России еще имеется свободная емкость рынка, поскольку отечественная онлайн-торговля по-прежнему остается не консолидированной (доля трех крупных маркетплейсов меньше трети рынка, например, доля Ozon - 9\%) против, например китайского e-commerce (два самых крупных маркетплейса обеспечивают более половины оборота рынка).

Нереализованный потенциал развития российских электронных торговых площадок аккумулирует в себе ресурс постепенного увеличения их давления на поставщиков, так как доля Интернет-торговли в России не превышает 9\% (41 из 456 млрд. долл. в 2020 г.) от розничной торговли в целом против 20\% в США или $27 \%$ в Китае [6-8]. Можно предположить, что именно консолидация отечественного онлайн-ритейла в рамках трех-четырех операторов создаст сбалансированное единообразие в тарификации, что ограничит практику ценового демпинга, но может усилить давление на мерчантов.

Так, развитие российского Ozon по модели Amazon через агрессивное наращивание клиентской базы и увеличение выручки имеет в своей основе стратегический расчет на постепенное снижение уровня постоянных затрат на один заказ, что обеспечит экспоненциальный выход на прибыль. Сегодня захват рынка со стороны Ozon, жесткая конкуренция и рост инвестиций в развитие торгово-складской инфраструктуры увеличивают убытки из-за роста операционных расходов компании.

Можно констатировать, что экспансивный рост Интернет-торговли в России, в том числе стимулированный распространением COVID-19 привел к существенному расширению инвестиционной емкости развития отечественного e-commerce [10,11]. На конец 2021 г. Wildberries располагает 450 тыс. кв. м. складских площадей. На конец июля 2021 г. общая площадь распределительных центров Ozon составила 268 тыс. кв. м.: только в 2021 г. объем капитальных инвестиций Ozon в логистику составит 20-25 млрд. руб. Инвестиционные планы маркетплейса предполагают выход на 1 млн. кв. м. площадей уже в 2025-2026 гг.

Как показывает консенсус прогноз Bloomberg, «совокупные инвестиции компании за период со второго полугодия 2021 г. и в 2022-2023 гг. составят порядка 73 млрд. руб.»". При этом предполагается сокращение операционных убытков компании и выход на безубыточность по EBITDA в 2023 г.

Концепция снижения стоимости доставки в низкорентабельной онлайн-торговле на поверку постепенно теряет свою «теоретическую без- 


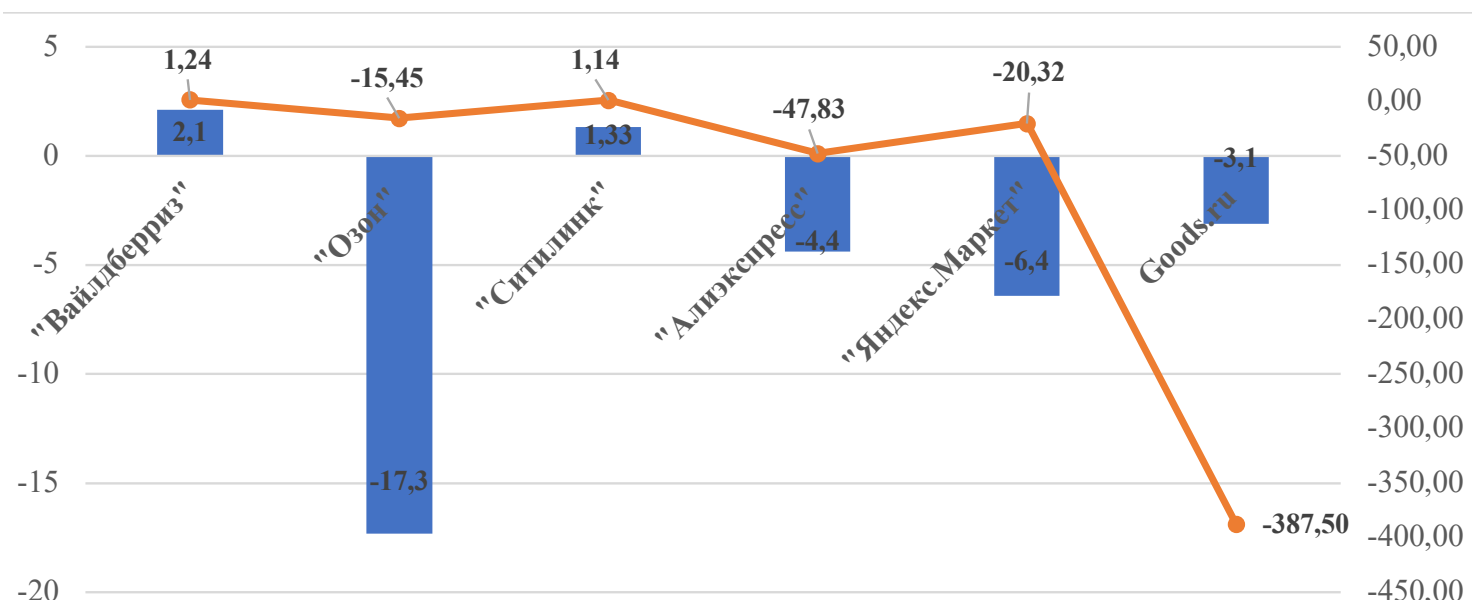

—_истая прибыль в 2020 г., млрд. руб. (правая шкала)

- Рентабельность, \% (левая шкала)

Puc. 2. Объем прибыли и рентабельность работы крупнейших интернет-магазинов в России по итогам 2020 г. [9, с. 46]

упречность» (рис. 2). Развитие онлайн-шопинга в России требует ввода новых мощностей, строительства фулфилмент- и сортировочных центров, развития инфраструктуры последней мили. При этом крайне сложно определить сценарий развития российского рынка Интернетторговли. От «рафинированных» китайского и американского вариантов его отделяет наличие множества сильных конкурентов, которых на старте своего институционального взросления не имели Amazon и Taobao, но имеет отечественный Ozon (Wildberries, AlieExpress, «Яндекс», «СберМегаМаркет» и др.). Так, в планах «AliExpress Россия» продолжение расширения инфраструктуры фулфилмент-центров в регионах РФ, мощности которых на периметре 20222024 гг. должны достигнуть 1 млн. кв. м.

Между тем, фактором эффективности развития логистической инфраструктуры Интернетторговли в ближайшие годы будет являться доступность РЦ и последней мили в регионах страны на уровне Москвы и Санкт-Петербурга. В 2020 г. по данным Data Insight при общем количестве постаматов и ПВ3 в 50 тыс. треть из них расположены в Москве и Московской области, а также Санкт-Петербурге и Ленинградской области [3]. Выравнивание охвата одной точкой последней мили для остальной части РФ на уровне столичных регионов потребует открытия дополнительно более 30 тыс. точек по стране.

Таким образом, экспресс-доставка и расширение проникновения в регионах как драйверы развития Интернет-торговли выступают одно- временно и факторами ограничения ее роста.

Во-первых, развитие последней мили и экспресс-доставки на уровне российских регионов представляется достаточно затратоемким даже при развитии сетки ПВЗ маркетплейсов по модели франчайзинга (80\% ПВ3 Ozon). На уровне научно-практической оценки этого ограничения эмпирически может возникнуть дилемма, в которой миллиардные инфраструктурные инвестиции в логистику онлайн-ритейла по уровню капиталоемкости могут превысить этот показатель в традиционной рознице.

В настоящее время, «на один доллар выручки приходится 0,23 долл. инвестиций в материальные активы для е-commerce платформ и около 0,1 долл. - для офлайн-ритейла» (по данным Amazon и Walmart) [1, с. 24]. То есть, относительный уровень кап. инвестиций на доллар выручки интернет-платформ вдвое превышает этот показатель в оффлайне и может быть выравнен только за счет опережающих темпов развития e-commerce платформ. Можно также предположить, что при смещении стратегического фокуса к выравниванию показателя рентабельности маркетплейсов, чувствительность к цене будет ниже в силу возрастания релевантности практики приобретения товаров онлайн для значительной части населения.

Во-вторых, продвижение в регионы с другим уровнем покупательской способности населения потребует от интернет-магазинов сохранения низких цен. Это также формирует риск-фактор ограниченных возможностей корректировки 
рентабельности интернет-платформ, которые не смогут существенно скорректировать цены после того, как достигнут максимального охвата рынка.

Довершая анализ потенциала прибылеобразования российских е-commerce платформ, следует отметить, что облачный сервис Amazon (AWS) обеспечивает 12\% выручки и 47\% общего операционного дохода Amazon. Для Alibaba его облачное подразделение Aliyun формирует 7\% выручки китайской компании. Запущенная в апреле 2019 г. российским Ozon подписка обусловлена, вероятно, более низким уровнем доходов населения РФ, а поступления от подписки пока не выделяются в отчетности маркетплейса.

В целом, можно резюмировать следующее. Безапелляционные представления о высокой эффективности экономики роста интернетплатформ не проходят проверку временем. Стратегии e-commerce платформ с региональным фокусом развития и упором на масштабирование логистической инфраструктуры потребуют экономически грамотной реализации в условиях жесткой конкуренции, сохранения низких цен и непрерывного сокращения расходов на доставку одного заказа.

Специфика развития российского рынка Интернет-торговли ограничивает прямые параллели с развитием американского и китайского е-commerce, поскольку мы имеем «свою» потребительскую базу с относительно (Тaobao) более низкой плотностью распределения при отсутствии высокоприбыльных облачных подразделений по аналогии с AWS Amazon или Aliyun Alibaba.

Как было отмечено выше, в перспективе маркетплейсам будет сложно скорректировать рентабельность, что сильно секвестирует для них возможности максимизации прибыли после завершения экстенсивной фазы активного роста. В период август 2020 г. - август 2021 г. Ozon фактически утроил базу активных мерчантов с 13,5 тыс. до 50 тыс. (Wildberries - 90 тыс. продавцов), но вероятно будет ограничен в возможности наращивания давления на них с целью повышения прибыльности продаж. При этом, на периметре ближайших пяти лет Ozon может повторить траекторию Amazon, который смог за пять лет к 2020 г. опережающим темпом на порядок увеличить объем прибыли при росте выручке американской площадки за этот период в 2,8 paза.
Важно отметить, что на рынке развиваются две бизнес-модели торговых площадок, в которых поставщики предлагают маркетплейсу продукцию по схеме «1P» (first-party relationship площадка перепродает товар покупателю) и «3Р» (third-party relationship - поставщик самостоятельно реализует продукцию через маркетплейс). Ввиду отсутствия товарных запасов по схеме «3Р» возможность более быстрого масштабирования платформы дополняется и более высокой прибыльностью роста по такой схеме, когда маркетплейс работает как витрина, не предоставляя клиенту опцию доставки. При этом в текущей фазе роста и привлечения мерчантов объем прибыли платформ по схеме «1Р» при общеотраслевой тенденции оптимизации и снижения комиссий может оказаться больше, чем по схеме «3Р». То есть, при «1Р» маркетплейс расширяет опции и ценностное предложение для клиента, что обеспечивает возможности более прибыльного дифференцированного ценообразования плюс объемный прирост выручки на базе динамичного увеличения клиентской базы. В случае модели «3Р» комплекс опций более срезан, что ограничивает объем комиссий маркетплейса и позволяет привлекать преимущественно клиентов, располагающих функционалом для самостоятельного сбыта.

Распределение рыночной власти в транзакционных схемах взаимодействия «поставщик - маркетплейс» сегодня смещается в пользу е-commerce платформ. Так, в практике работы российских площадок они не контролируют и не ограничивают сбыт продукции производителя другими перепродавцами, перекладывая решение этих вопросов на поставщика на уровне стратегического выстраивания им системы дистрибуции товара. В работе зарубежных площадок, например, Amazon через мониторинг цен на других площадках, в том числе в оффлайне развивает практику штрафования продавцов, которые предлагают свою продукцию вне рамок платформы по более низкой цене вне зависимости от схемы поставки («1Р» или «3Р», где от мерчанта ничего не зависит).

Таким образом, современное развитие e-commerce платформ в России выходит на этап капиталоемкого расширения логистической инфраструктуры и ее вывода в регионы. Это фактически барьер входа на рынок в виде затратоемкой логистики, закрепляя рыночную власть за отдельными крупными цифровыми площад- 
ками, что формируют пропорции будущей концентрации капитала в онлайн-торговле, фактически повторяя консолидированную форму этого рынка в зарубежных е-commerce.

Как показал анализ вышеприведенной фактографии развития отечественной Интернетторговли, теоретически смелое допущение о более низкой стоимости продаж через Интернет не имеет четкого эмпирического подтверждения. Рост платформ сопряжен с более масштабными инвестициями в торгово-распределительную инфраструктуру, что формирует недостаточно оптимальную экономику затрат в росте и масштабировании онлайновой розницы. Удорожание стоимости доставки через Интернет формирует внеэкономические императивы улучшения экономики цифровой торговли, при которых соразмерность цены в оффлайне и онлайне будет обеспечивать привлекательность последнего только через многолетнее формирование устойчивых паттернов потребительского поведения, позиционирующих в сознании клиента онлайнпокупку как более удобную.

Кроме того, высокая скорость масштабирования онлайн-платформ может кратно сократить удельные издержки на доставку одного заказа, что имеет место в работе Ozon, который за год более чем на четверть снизил такие расходы по сравнению с концом 2020 г. несмотря на активное строительство складских мощностей.

Стратегические маркеры развития российских маркетплейсов сегодня ориентированы на преодоление новых ограничений, связанных с выходом в регионы страны, розничный рынок которых имеет более слабую потребительскую базу, что требует дополнительного снижения цен. Все это увеличивает экономический вычет из потенциальной прибыли площадок, что апо- стериори снизит результативность их масштабирования при охвате регионального торгового пространства.

Практика рыночного эволюционирования цифровой логистики начинает значительно отклоняться от научно обозначенных для нее ранее рамок экономической эффективности, что в эмпирическом пределе будет формировать иные менее широкие перспективы развития Интернет-торговли на институциональном уровне. На горизонте ближайших пяти лет мы увидим более сложный расклад в развитии отечественных маркетплейсов, ограничения по прибыли, а также нетривиальную связку онлайна и оффлайна, баланс развития которых является трудно прогнозируемым.

Обозначенные в настоящей статье проблемы текущей рыночной трансформации Интернетторговли в России формируют емкий фактографический задел, практико-ориентированное осмысление которого дает широкое поле возможностей для проблемно-ориентированной постановки, измерения и научно-практического решения различных проблем рыночной трансформации логистики е-commerce в России. На институциональном уровне мы увидим новую конфигурацию рынка, консолидированная форма которого будет «взламываться» сильными нишевыми электронными площадками, повторяя историю их успеха во Франции или Китае. Симбиоз такой фактографии на стыке теории и практики уже сегодня определяет исследовательскую оптику более сложного научного поиска и анализа, которая в корне отлична от более «мягких» научных постановок и видения проблем среднесрочной трансформации отечественного е-commerce в системе логистических исследований 2010-х гг.

\section{Библиографический список}

1. Безуглова В. Большие площадки для роста маленьких продавцов // Эксперт. 2021. № 42. - С. $23-25$.

2. Воблая И.Н., Деменко Д. А. Интернет-торговля как элемент цифровой экономики: отечественный и зарубежный опыт // Цифровая экономика: проблемы и современные тренды. Материалы всероссийской научнопрактической конференции. Под общей редакцией Е.Н. Сейфиевой. 2020. С. 365-370.

3. Глаз Ю.А., Бережная О. В., Марцева Т. Г. Исследование влияния организации и технологии экспресс-доставки товаров на развитие современной Интернет-торговли // Экономические системы. 2021. Т. 14. № 2. С. 75-83.

4. Ибрагимхалилова Т.В.Интернет-торговля: формы, типы, стратегии // Инновационные векторы цифровизации экономики и образования в регионах России. Сборник научных статей по материалам Всероссийской научно-практической конференции. Ставрополь, 2021. С. 269-274. 
5. Михайлюк, М.В. Демпинг и передел рынка как среднесрочное следствие будущего инвестиционного роста логистической инфраструктуры маркетплейсов в России // Интеграционные процессы в науке в современных условиях: сборник статей Международной научно-практической конференции (25 марта 2019 г, г. Оренбург). / М. В. Михайлюк. - Уфа: Аэтерна, 2019. - С. 49-55.

6. Михайлюк, М.В. Тенденции и направления развития логистики торговых площадок в е-commerce Рocсии / М. В. Михайлюк // Общество. - 2019. - № 1 (12). - С. 37-41.

7. Михайлюк, М.В.Цифровая трансформация рынка: маркетинговые потенциал и институциональнорыночные особенности развития онлайн-продаж / М. В. Михайлюк // Экономика и предпринимательство. 2020. - № 11. - С. 725-728.

8. Москвитина А. Э. Особенности рынка Интернет-торговли в России // Е-Scio. 2021. № 2 (53). С. $383-387$.

9. Обухова E. Ozon: прибыль на горизонте? // Эксперт. 2021. № 38. - С. 44-49.

10. Сакулян С.А. Анализ рынка российской Интернет-торговли в 2021 году // Актуальные научные исследования в современном мире. 2021. № 10-3 (78). С. 130-133.

11. Холмовский С.Г. Развитие российского рынка фулфилмента услуг как следствие роста Интернет-торговли // Baikal Research Journal. 2020. T. 11. № 1. С. 7.

12. Чиназирова С.К., Тлехурай-Берзегова Л.Т., Бюллер Е.А. Механизмы ценообразования на рынке ИнтернетТорГОВЛИ // ПРОБЛЕМЫ И ПЕРСПЕКТИВЫ РАЗВИТИЯ РОССИИ: МОЛОДЕЖНЫЙ ВЗГЛЯД В БУДУЩЕЕ. сборник научных статей 4-й Всероссийской научной конференции. Курск, 2021. С. 274-278. 